\title{
Synthetic and theoretical studies of novel ring closure and ring opening reactions
}

\author{
José Sepúlveda-Arques $^{\mathrm{a}^{*}}$ and M. Eugenia González-Rosende ${ }^{\mathrm{b}}$ \\ ${ }^{a}$ Departamento de Química Orgánica, Universidad de Valencia, Avda. Vicent Andrés Estellés \\ s/n, 46100 Burjassot, Valencia, Spain \\ . Departamento de Química, Bioquímica y Biología Molecular, Universidad Cardenal Herrera- \\ CEU, 46113 Moncada, Valencia, Spain \\ E-mail: jose.sepulveda@uv.es
}

\begin{abstract}
Ring closure and ring opening reactions are in many cases useful synthetic procedures in organic chemistry. They allow the preparation of complex molecules with high stereoselectivity and good yields. Mechanistic and theoretical studies have been carried out on the transformation of 2-aminopyrimidines into imidazo[1,2-c]pyrimidines and guanidines, respectively, through ring closure and ring opening reactions, as well as the transamidation reactions through the ring closure and ring opening of guanidine derivatives, which constitute novel synthetic methods.
\end{abstract}

Keywords: Imidazopyrimidines, guanidines, Michael addition, ring closure, ring opening, transamidation reaction

\section{Contents}

1. Novel synthesis of imidazo[1,2-c]pyrimidines

2. Synthesis of guanidines by ring opening of dihydropyrimidines

3. New transamidation reaction through ring closure and ring opening of guanidine derivatives

\section{Introduction}

In the course of a project directed towards the synthesis of imidazo[1,2-a]pyrimidines using 2aminopyrimidines as starting materials, we found novel synthetic methods to obtain imidazo[1,2c]pyrimidines and guanidines, which took place through ring closure and ring opening reactions. As an extension of these studies, we also observed an unprecedented transamidation reaction of $N$-carboxamidomethyl- $N^{\prime}$ tosylguanidines under mild conditions. 


\section{Novel synthesis of imidazo[1,2-c]pyrimidines}

During the preparation of a series of imidazo[1,2-a]pyrimidines for a pharmaceutical study, we obtained our first unintended result, the discovery of a new synthetic method of imidazo[1,2c]pyrimidines. ${ }^{1}$ The synthetic target of our project was the preparation of polyfunctionalized imidazo[1,2-a]pyrimidines with an amino group at the C-2, structurally related to Enviroxime, a benzimidazole derivative with strong in vitro antirhinoviral activity ${ }^{2}$ (Figure 1). Imidazo[1,2a]pyrimidines are important compounds in pharmaceutical chemistry as antiviral agents, ${ }^{3 a}$ inotropic and $\beta$-blocking agents, ${ }^{3 \mathrm{~b}}$ antibacterials, ${ }^{3 \mathrm{c}}$ antifungal agents, ${ }^{3 \mathrm{~d}}$ benzodiazepine receptor agonists, ${ }^{3 \mathrm{e}}$ and calcium channel blockers. ${ }^{3 \mathrm{f}}$ The synthesis of imidazo[1,2-a]pyrimidines has been widely investigated and one of the most common strategies uses 2-aminopyrimidine as the starting material. ${ }^{4}$ However, no synthesis of 2-amino substituted imidazo[1,2-a]pyrimidines were found in the literature, and we chose the method used by Bochis ${ }^{5}$ and Hamdouchi ${ }^{6}$ for the preparation of imidazo[1,2-a]pyridines, starting from 2-aminopyrimidines.

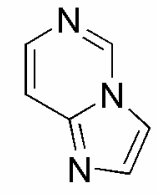

Imidazo [1,2-c]pyrimidines

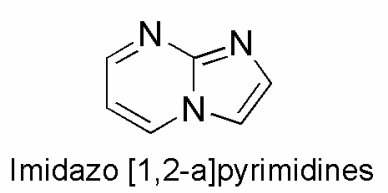

Imidazo [1,2-a]pyrimidines

\section{Figure 1}

Accordingly with the above procedure, the reaction of the 2-p-tosylaminopyrimidine 2 with the appropriate bromoacetamides 3 in the presence of Hünig's base in DMF provided the corresponding 2-tosylimino-1-substituted dihydropyrimidines $\mathbf{4}$ as major products. The higher yields in the endocyclic nitrogen alkylation in comparison with the $N$-exocyclic alkylation are in accordance with the literature, as it has been reported that 2-aminopyrimidines are predominantly alkylated at the ring nitrogen except when steric requirements of the alkyl halide are great enough to direct the reaction to the exocyclic nitrogen. ${ }^{7}$ On the other hand, it is known that acylations normally occur at the exocyclic nitrogen. ${ }^{8}$ When the alkylated products 4 were heated at reflux in trifluoroacetic anhydride as solvent, the imidazo[1,2-a]pyrimidines $\mathbf{5}$ were obtained. However, in the reaction of $\mathbf{2 B , C}$ with $\mathbf{3 b}-\mathbf{f}$ instead of the expected compounds $\mathbf{4}$, the hexahydroimidazo[1,2-c]pyrimidines 6 were isolated. On the other hand, by heating at reflux imidazo[1,2-c]pyrimidines 6 with trifluoroacetic anhydride in dichloromethane and $\mathrm{TsOH}$ as catalyst, the imidazo[1,2-a]pyrimidines 5 were afforded (Scheme 1). 


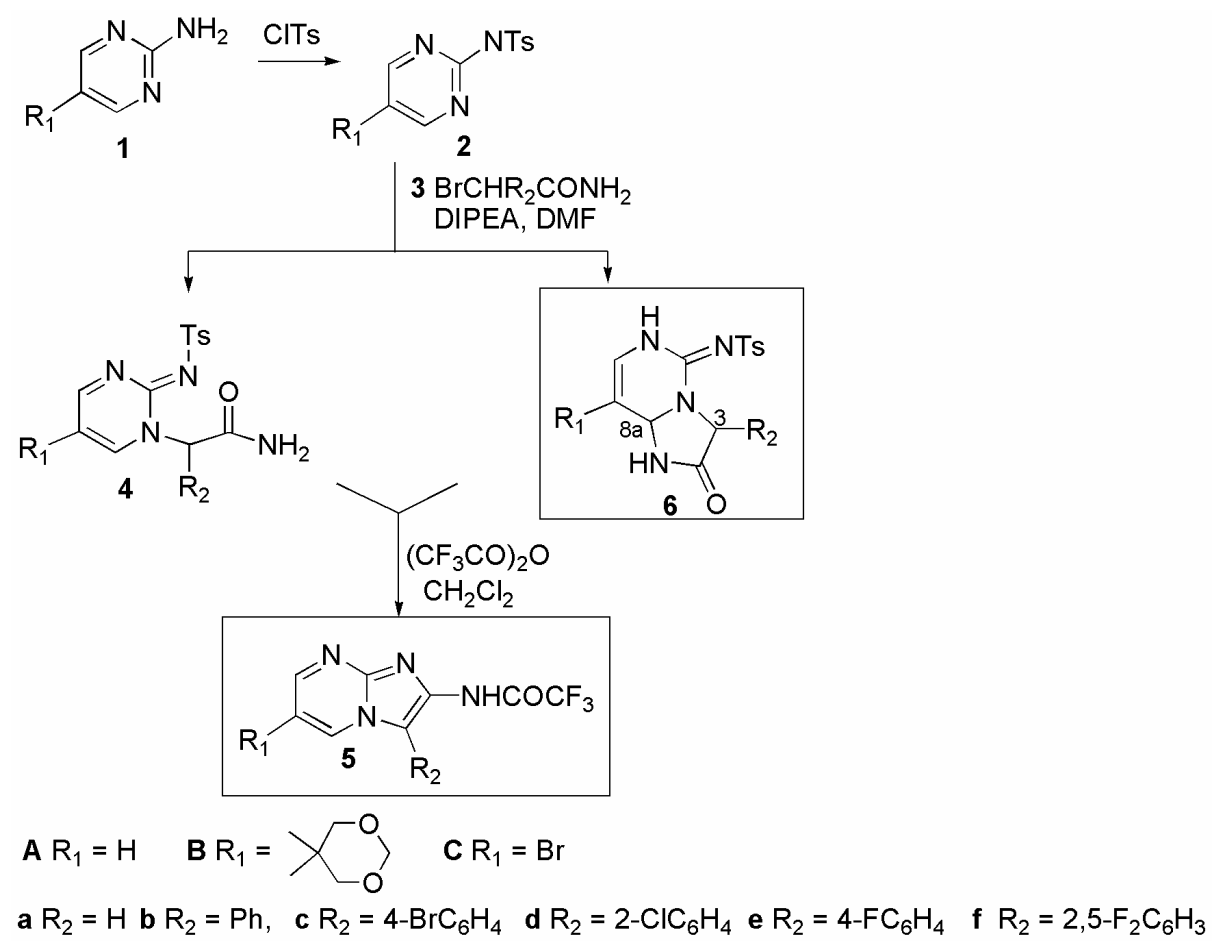

\section{Scheme 1}

Compounds 6 were characterized spectroscopically. The imidazo[1,2-c]pyrimidines have two stereocenters with $\mathrm{C}_{8 \mathrm{a}-\mathrm{H}}$ and $\mathrm{C}_{3-\mathrm{H}}$ in trans disposition. The X-ray crystallographic analysis of a single crystal of 6Ac confirmed the stereochemistry (Figure 2).

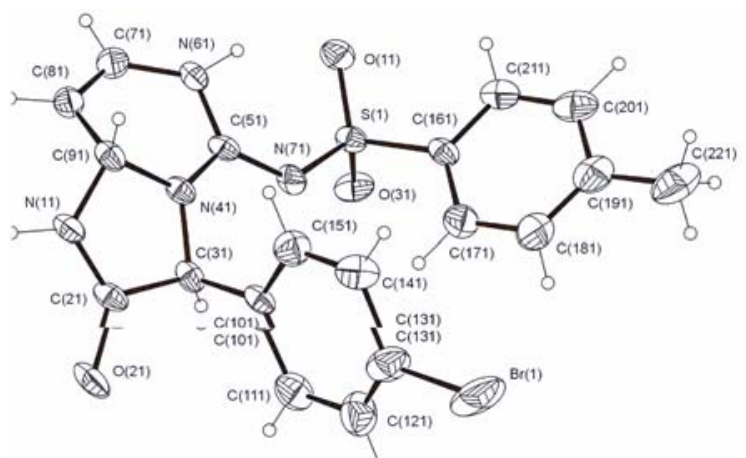

\section{Figure 2}

Imidazo[1,2-c]pyrimidine structural moiety presents potential interest as may be regarded as a 3-deazapurine with a bridgehead nitrogen atom in which $\mathrm{N}_{3}$ and $\mathrm{C}_{3 a}$ are interchanged. Several methods have been applied for the synthesis of imidazo[1,2-c]pyrimidines and the most frequently developed procedure involves the condensation of 4(6)-aminopyrimidine derivatives. $^{4 \mathrm{a}, \mathrm{f}}$ To the best of our knowledge, our finding was the first example of a synthesis of imidazo[1,2-c]pyrimidines starting from 2-aminopyrimidine. 
The formation of the imidazo[1,2-c]pyrimidines $\mathbf{6}$ is the result of a Michael addition of the carboxamide group to the $\alpha, \beta$-unsaturated imine system. The trans disposition of the $\mathrm{H}_{3}$ and $\mathrm{H}_{8 \mathrm{a}}$ hydrogens confirms that the addition of the amide to the unsaturated imine is diastereoselective with the nucleophilic attack occurring preferentially on the opposite face to the aryl substituent at $\mathrm{C}_{3}$ (Scheme 2).

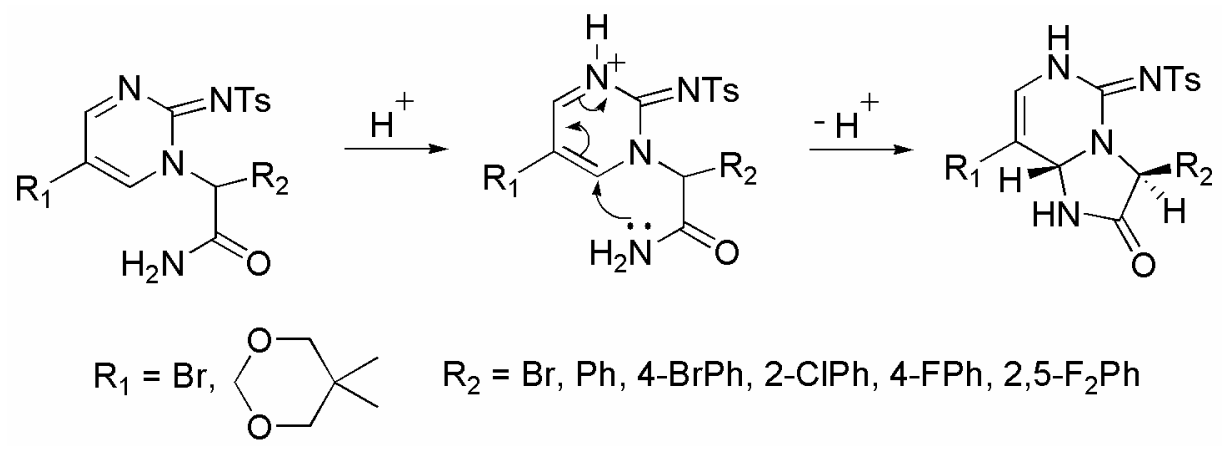

\section{Scheme 2}

The most relevant aspects on which we would like to emphasize of this novel synthetic method of imidazo[1,2-c]pyrimidines through an unusual Michael addition are the following:

1) A carboxamide group as nucleophile

2) An $\alpha, \beta$-unsaturated imine as electrophile

1) A carboxamide group as nucleophile

The nucleophilic attack of a carboxamide to an unsaturated system is not very frequent and the most common examples reported in the literature are intramolecular and intermolecular additions to $\mathrm{C}=\mathrm{N}$ double bonds. For instance, strongly electrophilic iminium species derived from pirrolidine, which undergo cyclization via intramolecular attack of an amido group ${ }^{9,10}$ (Scheme 3).

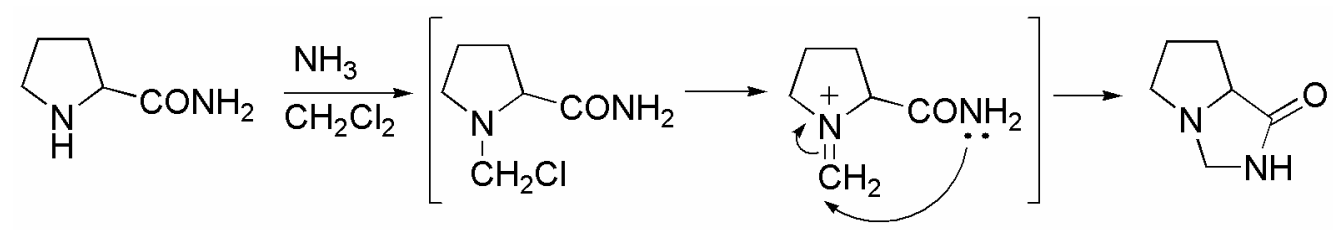

\section{Scheme 3}

A similar mechanism, under anhydrous acidic conditions, has been postulated for the formation of a polyheterocyclic compound in the reaction of glutaraldehyde with pipecotamide (2-piperidinecarboxamide) (Scheme 4). ${ }^{11}$ 


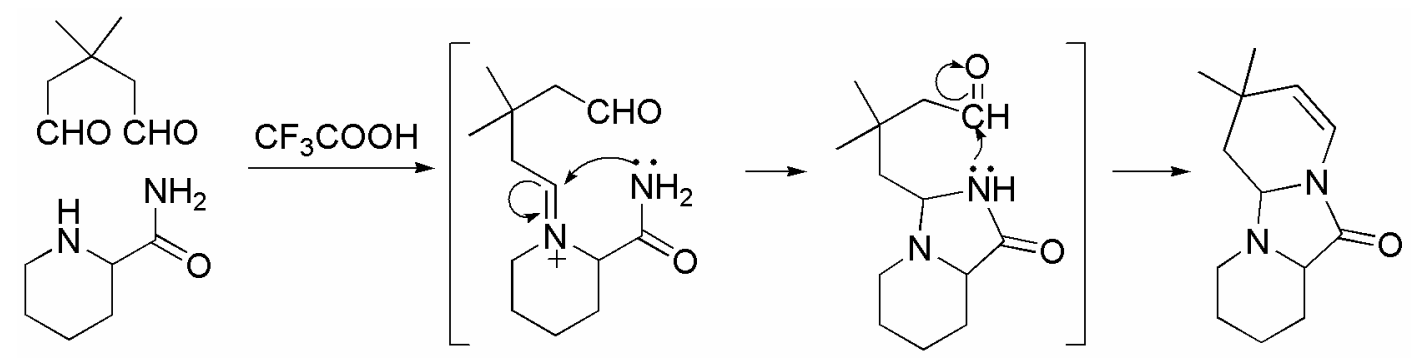

\section{Scheme 4}

Finally, examples of a nucleophilic attack of a carboxamide group to a $\mathrm{C}=\mathrm{N}$ are found in the field of antibiotics. In the Scheme 5 it is shown the synthesis of the hetacillin, prepared by the reaction of acetone on the commercially penicillin, ampicillin, ${ }^{12}$ and the synthesis of rolitetracycline, a derivative of tetracycline obtained via intermolecular addition of a carboxamide group to the iminium salt of pyrrolidine and formaldehyde. ${ }^{13}$<smiles>CC1(C)SC2C(NC(=O)C(N)c3ccccc3)C(=O)N2C1C(=O)O</smiles><smiles>CC1(C)SC2C(N3C(=O)C(c4ccccc4)NC3(C)C)C(=O)N2C1C(=O)O</smiles><smiles>CN(C)C1C(O)=C(C(N)=O)C(=O)C2(O)C(O)=C3C(=O)c4c(O)cccc4[C@@H](O)C3C[C@H]12</smiles><smiles>CC(=O)C1C2CCN1CC2C</smiles><smiles>CN(C)C1C(O)=C(C(=O)NCN2CCCC2)C(=O)[C@@]2(O)C(O)=C3C(=O)c4c(O)cccc4C(O)(O)C3C[C@H]12</smiles>

\section{Scheme 5}

2) An $\alpha, \beta$-unsaturated imine as electrophile

The other aspect of this novel synthetic method of imidazo[1,2-c]pyrimidines is the 1,4nucleophilic addition to an $\alpha, \beta$-unsaturated imine. One of the most intriguing and unexplored fields of nucleophilic addition reactions involves a conjugated addition to $\alpha, \beta$-unsaturated imino compounds and very few examples of such additions are found in the literature. A first example of a Michael-type addition to an unsaturated imine system is the condensation of triethylphosphite in presence of formic acid with aldimines, promoted by initial protonation at nitrogen and resulting in the formation of 1,4 -adducts. ${ }^{14}$ Similar additions of "in situ” generated diethyl trimethylsilyl phosphite to $N$-arylimines of cinnamaldehyde afford 1,2- adducts as sole products, mixtures of 1,2 and 1,4 adducts or exclusively 1,4 adducts, depending on the substitution pattern. ${ }^{15}$ Analogously, highly regioselective 1,2-additions are achieved with 
organolanthanum reagents generated in situ from lanthanide trichloride and alkyl lithium or allyl magnesium $^{16}$ (Scheme 6).

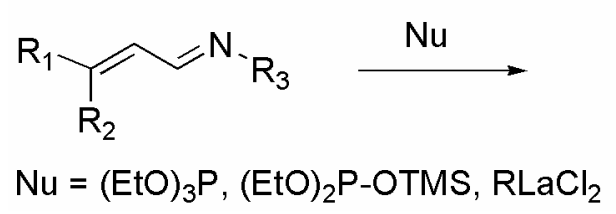

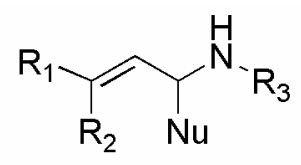

1,2-adduct<smiles>[R9]N=CCC([R])([R])[N]</smiles>

1,4-adduct

\section{Scheme 6}

Recently, double nucleophilic addition reactions in the presence of Lewis acids of ketene silyl acetals, allylstannanes and thiols to $\alpha, \beta$-unsaturated imines, via intermediary imino species, which are relatively difficult to be isolated and purified have been reported ${ }^{17}$ (Scheme 7).

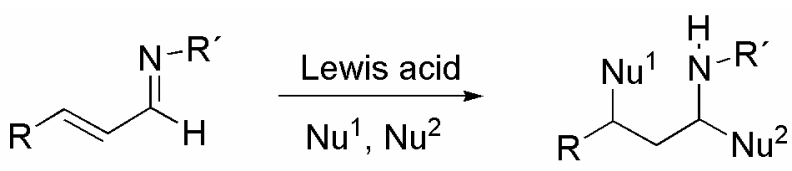

\section{Scheme 7}

In conclusion, we have presented a novel synthetic method of imidazo[1,2-c] pyrimidines 6 and a facile preparation of imidazo[1,2-a]pyrimidines 5 from $N$-alkylated 2tosyliminodihydropyrimidines $\mathbf{4}$, easily obtained from 2-aminopyrimidine. The potential antiinflamatory activity of imidazo[1,2-c] pyrimidines $\mathbf{6}^{18}$ and imidazo[1,2-a] pyrimidines $\mathbf{5}^{19}$ has been studied showing interesting pharmacological profiles. Theoretical studies on the ring closure of some dihydropyrimidines to afford imidazo[1,2-c]pyrimidines through the 1,4addition of a nucleophilic carboxamide group are in progress.

\section{Synthesis of guanidines by ring opening of dihydropyrimidines}

As imidazo[1,2-c]pyrimidines $\mathbf{I}$ were obtained from 2-tosylimino-1-carbamoylmethylpyrimidines II by an unsual intramolecular Michael addition of the carboxamide group to the $\alpha, \beta$-unsaturated imino system, we were intrigued to see if intermolecular Michael additions, under controlled conditions, with primary amines would take place on similar 1,2dihydropyrimidine systems II affording structures III. Moreover, since we found biological activity in imidazo[1,2-c]pyrimidines $\mathbf{I},{ }^{18}$ we considered it would be interesting the preparation of analogous molecules III with the functionality of the imidazo[1,2-c]pyrimidines I, but without the imidazo ring (Figure 3). 

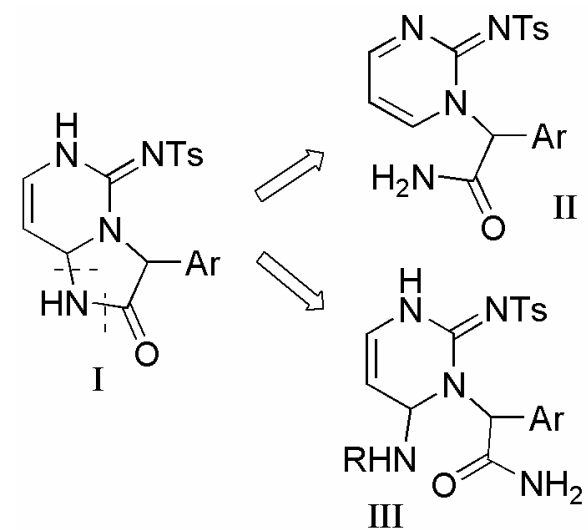

\section{Figure 3}

It is known that at least two categories of pyrimidines are prone to ring fission, albeit by a variety of mechanisms. The first group has decreased aromaticity because of a fixed system of double bonds as in 1,2-dihydro-2-imino-1-methylpyrimidines which undergoes Dimroth rearrangement involving ring fission in aqueous solution. The second group comprises pyrimidine itself in which the $\pi$ layer is depleted by the ring nitrogen atoms and more in particular, those pyrimidines bearing an additional electron-withdrawing group (Scheme 8). ${ }^{20}$

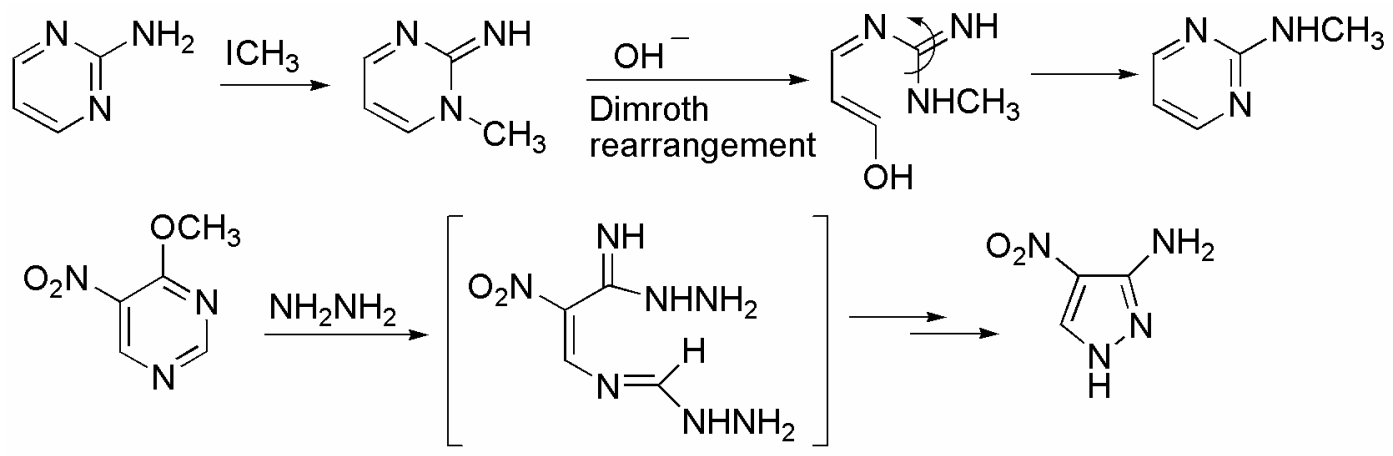

\section{Scheme 8}

In spite of the precedented regards, we were interested in investigating the reactivity of 2tosyliminodihydropyrimidines with primary amines. The substrates for this study were 4Aa and the analogous $N$-alkylated dihydropyrimidines containing a 1,4-disubstituted benzene ring $\mathbf{7 b}$-f, prepared for a pharmacological study. ${ }^{21}$ The reaction of the alkylated products $4 \mathbf{A a}$ and $\mathbf{7 b}$-f $\mathbf{f}$ with methylamine (g) at $-40{ }^{\circ} \mathrm{C}$ provided guanidines 8a-f in high yields (70-90\%), along with (Z)-3methylamino-2-propenal 9 (5-8\%) (Scheme 9). ${ }^{22}$ 


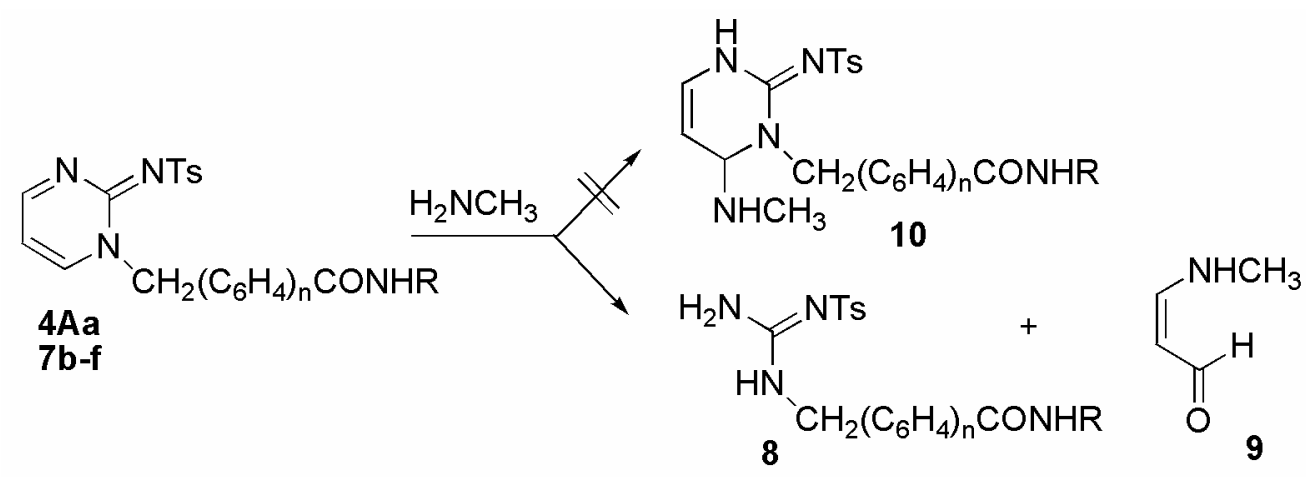

a $n=0, R=H ; b n=1, R=P h ; \mathbf{c} n=1, R=4-F P h ; d n=1, R=4-\mathrm{FPhCH}_{2} \mathrm{CH}_{2}$;

e $n=1, R=2,4-\mathrm{Cl}_{2} \mathrm{Ph} ; \mathrm{f} n=1, \mathrm{R}=2,4-\mathrm{Cl}_{2} \mathrm{PhCH}_{2} \mathrm{CH}_{2}$

\section{Scheme 9}

Numerous natural and non-natural guanidine derivatives have shown biological activity, making these compounds targets for drugs design and discovery, ${ }^{23}$ sulfonylguanidines are specially of great interest in medicinal chemistry. ${ }^{24}$ Classically, guanidines are obtained through intermediates such as thioureas, carbodiimides, chloroformamidines, dichloroisocyanides, carboxamidines or cyanamides and through Mitsunobu protocol. ${ }^{25}$

The formation of guanidines $\mathbf{8}$ was explained by the nucleophilic addition of methylamine at the ring carbon $\left(\mathrm{C}_{6}\right)$ of the 2-tosyliminopyrimidines $4 \mathbf{A a}$ and $\mathbf{7 b - f}$. Concomitant ring opening and further attack of the amine at $\mathrm{C}_{4}$ followed by $\mathrm{N}_{3}-\mathrm{C}_{4}$ bond cleavage would give guanidines 8 and the intermediate $\mathbf{1 1}$ isolated as the hydrolysed product (Z)-3-methylamino-2-propenal $\mathbf{9}$ (Scheme 10).

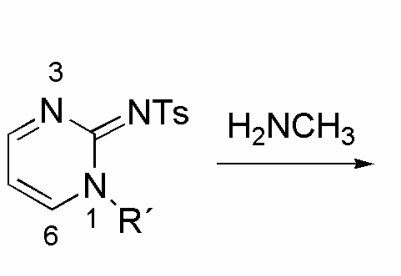

4Aa, $7 b-f$

$\mathrm{R}^{\prime}=\mathrm{CH}_{2}\left(\mathrm{C}_{6} \mathrm{H}_{4}\right)_{\mathrm{n}} \mathrm{CONHR}$

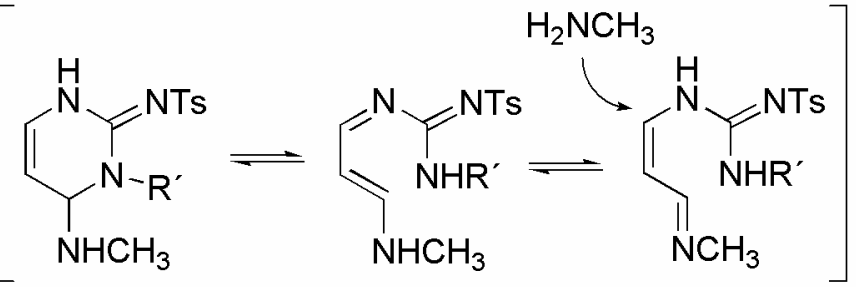

10<smiles>[3H][3H]</smiles><smiles>[R]NC(=N)N[13CH3]</smiles>

8

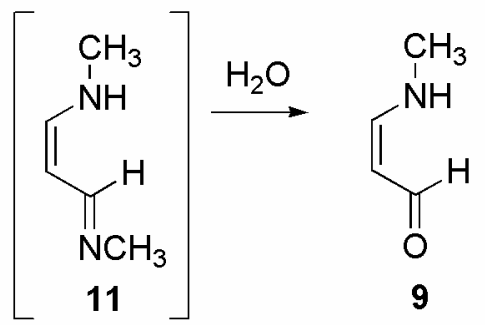

Scheme 10 
Inspection of the literature has shown that ring fission of pyrimidine systems was extensively studied in the sixties, ${ }^{20}$ and a close analogy with our result is the reaction of $1,2-$ dihydro-2-imino-1-methylpyrimidine with butylamine, studied by Brown, ${ }^{26}$ who obtained $1,3-$ dibutyliminopropane and "postulated" the loss of methylguanidine, which was "not isolated" (Scheme 11).

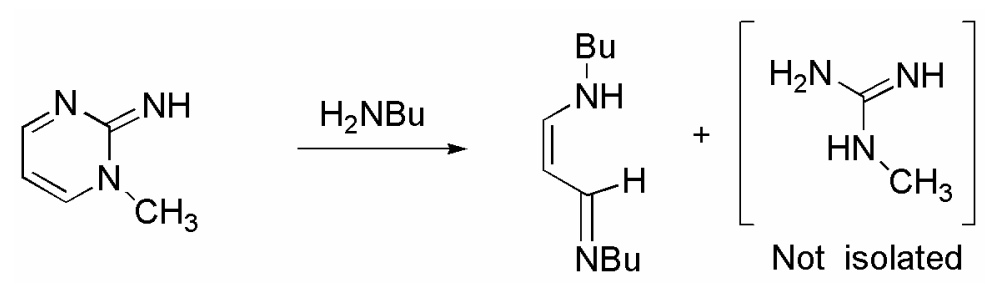

\section{Scheme 11}

In summary, the transformation of the 1,2-dihydro-2-toluenesulfonylimino- pyrimidines 4Aa and 7b-f into guanidines 8a-f, initiated by the ring opening of the dihydropyrimidine moiety constitutes a simple and efficient route to important substituted tosylguanidine derivatives.

\section{New transamidation reaction through ring closure and ring opening of guanidine derivatives}

In order to obtain a deeper insight of the transformation of compounds 4Aa and 7b-f into guanidines 8a-f by treatment with methylamine, which we have previously observed, and to extend the scope of this finding, we studied the behaviour of the dihydropyrimidine 4Aa with other alkyl primary amines as $n$-propyl and $n$-butylamine at room temperature. In these reactions the expected guanidine 8a was isolated in good yields (70 - 75 \%), however, surprisingly, when the reaction conditions were changed and dihydropyrimidine 4Aa was treated with the same amines under heating, the unexpected guanidines $\mathbf{1 2 a - c}$, resulting from a transamidation reaction, were obtained in moderate to good yield (50-64\%). Moreover, treatment of the guanidine 8a with methylamine (g) (acetonitrile, $50{ }^{\circ} \mathrm{C}$, sealed tube), and propyl and butylamine $\left(50{ }^{\circ} \mathrm{C}\right)$, afforded the same transamidated products 12a-c with good yields. To obtain unequivocal evidence for the structure of compounds $\mathbf{1 2}$ and confirm the proposed transamidation reaction, guanidines 12 were alternatively synthesized from the ester $\mathbf{1 3}$ by treatment with alkyl amine at room temperature (Scheme 12). ${ }^{27}$ 


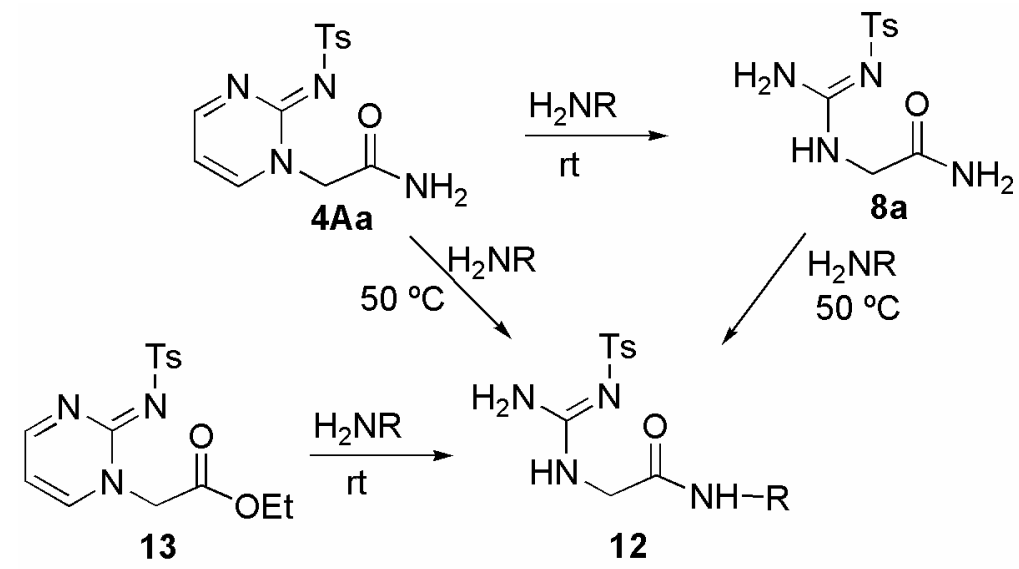

$\mathbf{a}: \mathrm{R}=\mathrm{Me}, \mathbf{b}: \mathrm{R}=\mathrm{Pr}, \mathbf{c}: \mathrm{R}=\mathrm{Bu}$

\section{Scheme 12}

This unprecedented intermolecular transamidation reaction of guanidines 8 into guanidines 12 represents a new and important synthetic strategy. Transamidation is a useful tool in synthetic organic chemistry. Direct transamidation reactions with amines intramolecularly or intermolecularly are known to be difficult as the amide functional group is resonance stabilized and they are restricted to special conditions and requirements. In the literature there are examples of these reactions, but all of them take place under special requirements such as ring expansion of lactams ${ }^{28}$ and oxosultams, ${ }^{29}$ lower carboxamides, ${ }^{30}$ intramolecular processes, $^{31}$ activated amides, ${ }^{32}$ catalytic conditions (enzymatic, ${ }^{33}$ Lewis acid catalysis ${ }^{34}$ ) or high temperatures, ${ }^{35}$ and critical $\mathrm{pH}^{36}$ Transamidation reactions with $N$-sulfonamide linkers have been applied in peptide synthesis in solid phase. ${ }^{37}$

The formation of guanidines 12, which we obtained by a smooth intermolecular transamidation, was explained to occur through the intermediacy of a CO-N-SO 2 substructure by a mechanism which supposes a sulphonamide-amide intramolecular interaction and formation of the imidazolidinone 14 (Scheme 13).

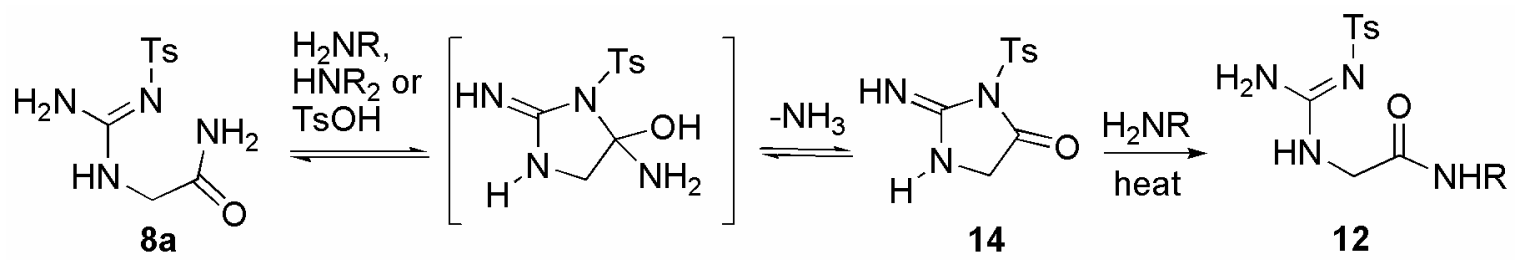

\section{Scheme 13}

The proposed mechanism through a ring closure and subsequent ring opening by the nucleophilic attack of the amine to afford guanidines $\mathbf{1 2}$ agrees with mechanisms reported in the literature for known transamidations, such as intramolecular transamidation reaction with amides 
containing the structural element $\mathrm{CO}-\mathrm{N}\left(\mathrm{CH}_{3}\right)-\mathrm{N},{ }^{38}$ intermolecular transamidation promoted by intramolecular activation $^{31 \mathrm{e}}$ or the ring opening of the highly strained and reactive oxosultams. ${ }^{29}$ To confirm the postulated mechanism, we examined the reaction of dihydropyrimidine 4Aa and guanidine $8 \mathrm{a}$ with secondary amines $\left(\mathrm{Me}_{2} \mathrm{NH}, \mathrm{Et}_{2} \mathrm{NH}, \mathrm{i}-\mathrm{Pr}_{2} \mathrm{NH}\right)$. In this case the imidazolidin-4one 14 was obtained and no transamidated guanidine was isolated (Scheme 14).

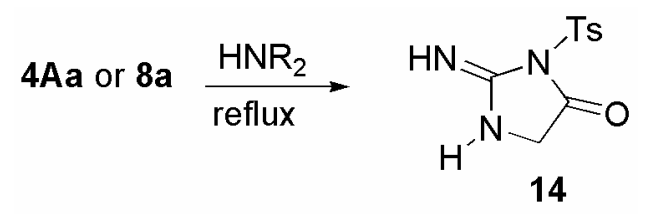

\section{Scheme 14}

Interestingly, our result is different from Brown's result, ${ }^{26}$ who obtained the Dimroth rearrangement product $\mathbf{1 5}$ in the reaction of 2-imino-dihydropyrimidine with diethylamine. The formation of 2-methylaminopyrimidine $\mathbf{1 5}$ is explained by the author via the intermediates 16 and 17. The loss of methylguanidine in the final step of primary amines addition through the intermediate 18 would be impossible according to Brown in the case of secondary amines, where the intermediate $\mathbf{1 9}$ would be involved and the recyclization step takes place from the intermediate 17 affording the Dimroth compound. Probably, in our case the electronwithdrawing effect of the tosyl group makes difficult the nucleophilic attack of the nitrogen necessary for the recyclization step (Scheme 15).

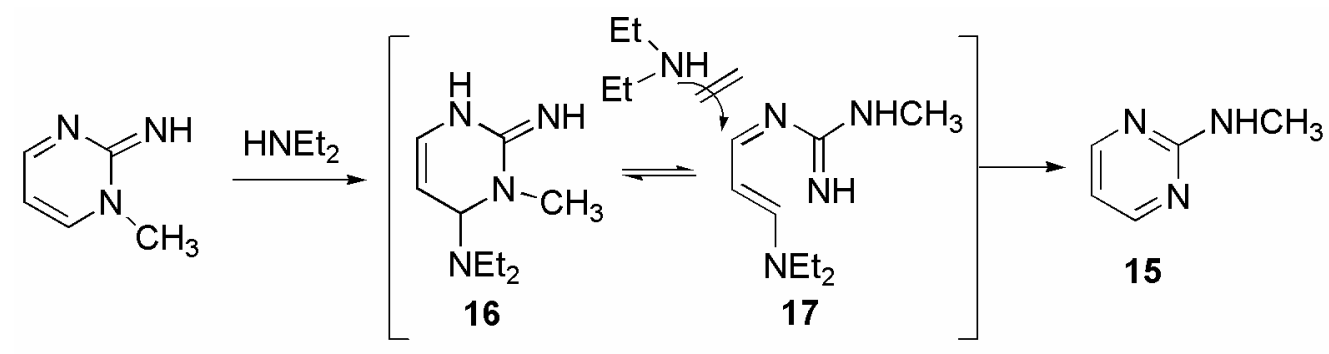

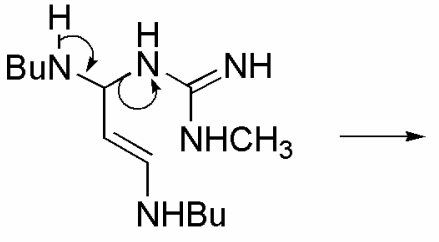

18

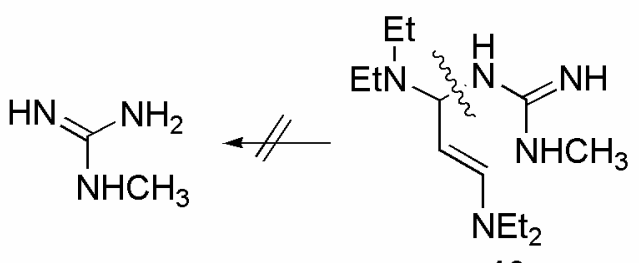

19

\section{Scheme 15}

In order to verify whether the cyclization product $\mathbf{1 4}$ could be the key intermediate in the transformation of dihydropyrimidine 4Aa and guanidine $\mathbf{8 a}$ into the transamidation compounds 12, we investigated the reaction of $\mathbf{1 4}$ with primary alkyl amines (methyl, propyl and 
butylamine) at reflux temperature. In all cases, guanidines 12a-c were quantitatively obtained. However, in the reaction of $\mathbf{1 4}$ with a secondary amine as dimethylamine under the same conditions the starting material was recovered even under extended reaction times and no traces of compound 12d could be detected (Scheme 16).
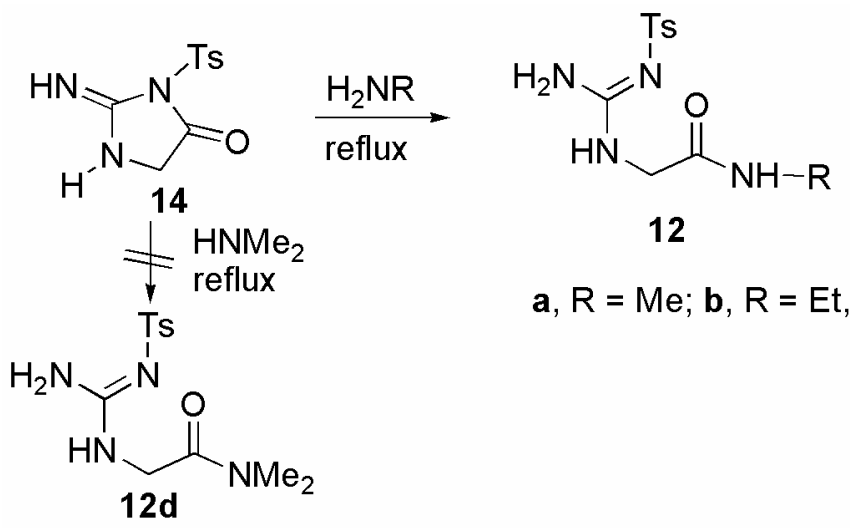

$\mathbf{a}, \mathrm{R}=\mathrm{Me} ; \mathbf{b}, \mathrm{R}=\mathrm{Et}, \mathbf{c}, \mathrm{R}=\mathrm{Pr}$

\section{Scheme 16}

Actually, to the best of our knowledge, the transformation of guanidines 8 into guanidines 12 is a novel example of a transamidation reaction under mild conditions. It may be considered as a simple, efficient and facile method for the direct conversion of non activated $\mathrm{N}$ unsubstituted carboxamides to secondary carboxamides. Theoretical and synthetic studies are in progress in order to investigate the scope and limitations of this useful transformation.

\section{Acknowledgements}

We thank the Ministery of Science and Technology (Project BQU2003-01756) for financial support.

\section{References and Notes}

1. Acero-Alarcón, A.; Armero-Alarte, T.; Jordá-Gregori, J. M.; Rojas-Argudo, C.; ZaballosGarcía, E.; Server-Carrió, J.; Ahjyaje, F.Z.; Sepulveda-Arques, J. Synthesis 1999, 12, 2124.

2. Wikel, J. H.; Paget, C. J.; DeLong, D. C.; Nelson, J. D.; Wu, C. Y. E.; Paschal, J. W.; Dinner, A.; Templeton, R. J.; Chaney, M. O.; Jones, N. D.; Chamberlin, J. W. J. Med. Chem. 1980, 23, 368.

3. (a) Gueiffier, A.; Lhassani, M.; Elhakmaoui, A.; Snoeck, R.; Andrei, G.; Chavignon, O.; Teulade, J-C.; Kerbal, A.; Essassi, E. M.; Debouzy, J-C.; Witvrouw, M.; Blache, Y.; Balzarini, J. De Clercq, E.; Chapat, J-P. J. Med. Chem. 1996, 39, 2856. (b) Barraclough, P.; 
Smith, S. J. Chem. Research (S) 1995, 56; Spitzer, W. A.; Victor, F.; Pollock, G. D.; Hayes, J. S. J. Med. Chem. 1988, 31, 1590. (c) Rival, Y.; Grassy, G.; Michel, G. Chem. Pharm. Bull. 1992, 49, 1170. (d) Rival, Y.; Grassy, G.; Taudou, A.; Ecalle, R. Eur. J. Med. Chem. 1991, 26, 13. (e) Tully, W. R.; Gardner, C. R.; Gillespie, R. J.; Westwood, R. J. Med. Chem. 1991, 34, 2060. (f) Sanfilippo, P.J.; Urbanski, M.; Press, J. B.; Dubinsky, B.; Moore, J. B., Jr. J. Med. Chem. 1988, 31, 2221.

4. (a) Sliskovic, D. R. In Comprehensive Heterocyclic Chemistry; Katrizky, A. R.; Rees, C. W.; Scriven, E. F. V., Eds.; Pergamon Press: Oxford, 1996; Vol. 8, p 354. (b) Groebke, K.; Weber, L.; Mehlin, F. Synlett 1998, 661. (c) Bienaymé, H.; Bouzid, K. Angew. Chem. Int. Ed. 1998, 37, 2234. (d) Blackburn, C.; Guan, B. Tetrahedron Lett. 2000, 41, 1495. (e) Mandair, G. S.; Light, M.; Russell, A.; Hursthouse, M.; Bradley, M. Tetrahedron Lett. 2002, 43, 4267. (f) Katritzky, A. R.; Xu, Y-J.; Tu, H. J. Org. Chem. 2003, 68, 4935.

5. Bochis, R. J.; Olen, L. E.; Fischer, M.H.; Reamer, R. A. J. Med. Chem. 1981, 24, 1483.

6. Hamdouchi, C.; Blas, J.; Prado, M.; Gruber, J.; Heinz, B. A. Vance, L. J. Med. Chem. 1999, 42, 50.

7. (a) Angier, R. B.; Curran, W.V. J. Org. Chem. 1961, 26, 1891. (b) Overberger, C. G.; Kogon, I. C. J. Am. Chem. Soc. 1954, 76, 1065. (c) Bristow, N. W.; Charlton, P. T.; Peak, D. A.; Short, W. F. J. Chem. Soc. 1954, 616. (d) Guerret, P.; Jacquier, R.; Maury, G. Bull. Soc. Chim. Fr. 1972, 3503. (e) Gray, A. P.; Heitmeier, D. E. J. Am. Chem. Soc. 1959, 81, 4347. (f) Undheim, K.; Benneche, T. In Comprehensive Heterocyclic Chemistry; Katrizky A. R., Rees, C. W., Scriven, E. F. V., Eds.; Pergamon Press: Oxford, 1996; Chapter 6.02, pp 114 and references therein.

8. Huntress, E. H.; Walter, H. C. J. Org. Chem. 1952, 87, 223.

9. Federsel H.-J.; Könberg, E.; Lilljequist, L.; Swahn, B.-M. J. Org. Chem. 1990, 55, 2254.

10. Polonski, T. Tetrahedron 1985, 41, 611.

11. Kukla M. J.; Breslin, H. J. J. Org. Chem. 1987, 52, 5046.

12. Panetta C. A.; Pesh-Imam, M. J. Org. Chem. 1972, 37, 302.

13. Gottstein, W. J.; Minor, W. F.; Cheney, L. C. J. Am. Chem. Soc. 1958, 81, 1198.

14. Teulada, M-P.; Savignac, P. Synthesis 1978, 1037.

15. Afarinkia, K.; Cadogan, J. I. G.; Rees, C. W. Synlett 1992, 123.

16. Qian, C.; Huang, T. S. J. Organometallic. Chem. 1997, 584, 143.

17. Shimizu, M.; Kamiya, M.; Hachiya, I. Chem. Lett. 2003, 32, 606.

18. Vidal, A.; Ferrándiz, M.L.; Ubeda, A.; Acero-Alarcón, A. Sepúlveda-Arques, J.; Alcaraz, M.J. J. Pharm. Pharmacol. 2001, 53, 1379.

19. Vidal, A.; Ferrándiz, Úbeda, A.; Acero-Alarcón, A.; Sepulveda-Arques, J.; Alcaraz, M. J. Inflamm. Res. 2001, 50, 317.

20. (a) El Ashry, E. S. H.; El Kilany, N.; Rashed, N. Assafir, H. Adv. Heterocl. Chem. 2000, 75, 79. (b) Brown, D. J.; Harper, J. S. J. Chem. Soc. (C) 1963, 1273. (c) Biffin, M. E. C.; Brown, D. J.; Porter, Q. N. Tetrahedron Lett. 1967, 2029. (d) Hayes, D. H.; Hayes-Baron, F. 
J. Chem. Soc. (C) 1967, 1528. (e) Biffin, M. E. C.; Brown, D. J.; Porter, Q. N. J. Chem. Soc. (C) 1968, 2159. (f) Van der Plas, H. C.; Jonjegan, H. Tetrahedron Lett. 1967, 4385.

21. Fernandez-Ferri, P.; Ubeda, A.; Guillén, I.; Lasri, J.; González-Rosende, M. E.; Akssira, M.; Sepúlveda-Arques, J. Eur. J. Med. Chem. 2003, 38, 289.

22. Lasri, J.; González-Rosende, M. E.; Sepúlveda-Arques, J. Synthesis 2003, 845.

23. (a) Rabinowitz, M. H.; Andrews, R. C.; Becherer, J. D.; Bickett, D. M.; Bubacz, D. C.; Conway, J. G.; Cowan, D. J.; Gaul, M.; Glennon, K. J. Med. Chem. 2001, 44, 4252. (b) Scozzafava, A.; Nicolae, A.; Maior, O.; Briganti, F.; Supuran, C. T. J. Enzym.Inhib. 1998, 14, 49. (c) Berlinck, R. G. S. Nat. Prod. Rep. 1996, 13, 377. (d) Laxma Reddy, N.; Hu, LH.; Cotter, R. E.; Fischer, J. B.; Wong, W. J.; McBurney, R. N.; Weber, E.; Holmes, D. L.; Wong, S. T.; Prasad, R. Keana, J. F. W. J. Med. Chem. 1994, 37, 260.

24. (a) Supuran, T.C.; Scozzafava, A.; Briganti, F.; Clare, B. W. J. Med. Chem. 2000, 43, 1793.

(b) Greenhill, J.L.; Lue, P. In Progress in Medicinal Chemistry; Ellis, G. P.; Luscombe, D. K., Eds.; Elsevier Science, 1993, Vol. 30, Chap. 5. (c) Burell, G.; Evans, J. M.; Hicks, F.; Stemp, G. Bioorg. Med. Chem. Lett. 1993, 3, 999.

25. (a) Zhang, J.; Shi, Y. Tetrahedron Lett. 2000, 41, 8075. (b) Feichtinger, K.; Zapf, C.; Sings, H. L.; Goodman, M. J. Org. Chem. 1998, 63, 3804. (c) Schlama, T.; Gouverneur, V.; Valleix, A.; Greiner, A.; Toupet, L.; Mioskowski, C. J. Org. Chem. 1997, 62, 4200. (d) Zhong, H. M.; Greco, M. N.; Maryanoff, B. R. J. Org. Chem. 1997, 62, 9326. (e) Yong, Y. F., Kowalski, J. A.; Lipton, M. A. J. Org. Chem. 1997, 62, 1540. (f) Barvian, M. R.; Showalter, H. D. H.; Doherty, A. M. Tetrahedron Lett. 1997, 38, 6799. (g) Levallet, C.; Lerpiniere, J.; Ko, S.Y. Tetrahedron 1997, 53, 5291. (h) Bossio, R.; Marcaccini, S.; Pepino, R. Tetrahedron Lett. 1995, 36, 2325. (i) Ramadas, K.; Srinivasan, N. Tetrahedron Lett. 1995, 36, 2841. (j) Lemcke, T.; Mesinger, P. Archiv. Pharm. 1995, 328, 269. (k) Kutepov, D.F.; Khokhlov, D. N.; Tuzhilina, V. L. Zh. Obshch. Khim. 1961, 31, 2825.

26. Brown, D. J; Ford, P. W.; Paddon-Row M. N. J. Chem. Soc.C 1968, 1452.

27. Lasri, J.; González-Rosende, M. E.; Sepúlveda-Arques, J. Org. Lett. 2003, 3851.

28. (a) Langlois, N. Tetrahedron Lett. 2002, 43, 9531. (b) Wasserman, H. H.; Matsuyama, H.; Robinson, R. P. Tetrahedron 2002, 58, 7177. (c) Begley, M. J.; Crombi, L.; Haigh, D.; Jones, D. H. R.; Osborne, S.; Webster, R. A. J. Chem. Soc. Perkin Trans 1 1993, 2027. (d) Kramer, U.; Guggisberg, A.; Hesse, M.; Schmid, H. Angew. Chem. Int. Ed.. 1977, 16, 861.

29. Todorova, T.; Linden, A.; Heimgartner, H. Helv. Chim. Acta 1999, 82, 354.

30. (a) Kraus, M. Synthesis 1973, 361. (b) Pettit, G. R.; Kalnins, M. V.; Liu, T. M. H.; Thomas, E. G.; Parent, K. J. Org. Chem. 1961, 26, 2563.

31. (a) García Martinez, A.; Teso Vilar, E.; García Fraile, A.; Martínez Ruiz, P.; Macías San Antonio, R.; Martínez Alcazar, M. P. Tetrahedron:Asymmetry 1999, 10, 1499. (b) Banfi, L.; Guanti, G.; Rasparini, M. Tetrahedron Lett. 1998, 39, 9539. (c) Doll, M. K.-H.; Jentgens, C.; Hofmann, R.; Guggisberg, A.; Bienz, S.; Hesse, M. Helv. Chim. Acta 1997, 80, 966. (d) Doll, M. K.-H.; Guggisberg, A.; Hesse, M. Helv. Chim. Acta 1996, 79, 541. (e) Suggs, J.W.; Pires, R. M. Tetrahedron Lett. 1997, 38, 2227. 
32. (a) Davidsen, S. K.; May, P. D.; Summers, J. B. J. Org. Chem. 1991, 56, 5482. (b) Grehn, L.; Gunnarson, K.; Ragnarsson, U. J. Chem. Soc. Chem. Commun. 1985, 1317. (c) Garcia, J.; González, J.; Segura, R.; Urpi, F.; Vilarasa, J. J. Org. Chem. 1984, 49, 3322. (d) Hendickson, J. B.; Bergeron, R. Tetrahedron Lett. 1973, 4607.

33. (a) Sergeeva, M. V.; Mozhaev, V.V.; Rich, J. O.; Khmelnitsky, Y. L. Biotechnol Lett. 2000, 22, 1419. (b) Gotor, V.; Brieva, R.; González, C.; Rebolledo, F. Tetrahedron 1991, 47, 9207.

34. (a) Bon, E.; Bigg, D. H.; Bertrand, G. J. Org. Chem. 1994, 59, 4035. (b) Eldred S.E.; Stone D.A.; Gellman S.H.; Stahl S.S. J. Am. Chem. Soc. 2003, 125, 3422.

35. Galat, A.; Elion, G. J. Am. Chem. Soc. 1943, 65, 1566.

36. Kirk, K. L.; Cohen, L. A. J. Am. Chem. Soc. 1972, 94, 8142.

37. (a) McMinn, D. L.; Greenberg, M. M. Tetrahedron Lett. 1997, 38, 3123. (b) Bradly, J. B.; Virgilio, A. A.; Ellman, J. A. J. Am. Chem. Soc. 1996, 118, 3055.

38. Guggisberg, A.; Dabroswki, B.; Kramer, U.; Heidelberger, C.; Hesse, M.; Schmid, H. Helv. Chem. Acta, 1978, 61, 1039. 